\title{
Proportion and mortality of Iranian diabetes mellitus, chronic kidney disease, hypertension and cardiovascular disease patients with COVID-19: a meta-analysis
}

\author{
Hamid Mirjalili ${ }^{1}$ - Seyed Alireza Dastgheib ${ }^{2}$ - Seyed Hossein Shaker ${ }^{3} \cdot$ Reza Bahrami $^{4} \cdot$ Mahta Mazaheri $^{5,6}$. \\ Seyed Mohamad Hossein Sadr-Bafghi ${ }^{7}$. Jalal Sadeghizadeh-Yazdi ${ }^{8} \cdot$ Hossein Neamatzadeh $^{5,6}$
}

Received: 18 November 2020 / Accepted: 14 February 2021 / Published online: 26 February 2021

(C) Springer Nature Switzerland AG 2021

\begin{abstract}
Background Currently, the number of patients with SARS-COV-2 infection has increased rapidly in Iran, but the risk and mortality of SARS-COV-2 infection in Iranian patients with diabetes mellitus (DM), chronic kidney disease (CKD), hypertension and cardiovascular diseases (CVDs) still not clear. The aim of this meta-analysis was to estimate the proportion and mortality of SARS-COV-2 in these patients.

Methods A comprehensive literature search was carried out in PubMed, Web of Sciences, Cochrane Library, EMBASE, CNKI, SciELO, and other databases to identify all relevant studies published up to 10 January, 2020. The proportion and mortality in the patients were assessed by odd ratio (OR) and the corresponding $95 \%$ confidence interval $(95 \% \mathrm{CI})$.

Results A total of ten case-series including 11,755 cases with SARS-COV-2 infection and 942 deaths were selected. Among them, there were total of 791 DM patients with 186 deaths, 225 CKD patients with 45 deaths, 790 hypertension cases with 86 deaths, and 471 CVDs cases with 60 deaths. Pooled data revealed that the proportion of SARS-COV-2 infection in the patients with hypertension, DM, CVDs and CKD were $21.1 \%, 16.3 \%, 14.0 \%$ and $5.0 \%$, respectively. Moreover, the SARS-COV2 infection were associated with an increased risk of mortality in DM $(\mathrm{OR}=0.549$, CI $95 \% 0.448-0.671, \mathrm{p} \leq 0.001)$ and $\mathrm{CKD}$ $(\mathrm{OR}=0.552,95 \% \mathrm{CI} 0.367-0.829, \mathrm{p}=0.004)$ patients, but not hypertension and CVDs. There was no publication bias.

Conclusions Our pooled data showed that the proportion of SARS-COV-2 infection was the highest in the Iranian patients with hypertension $(21.1 \%)$ followed by DM (16.3\%), CVDs (14.0\%) and CKD (5.0\%). Moreover, DM and CKD in patients with SARS-COV-2 infection were associated with a 0.549 and 0.552 -fold increase in mortality, respectively. Clinicians in Iran should be aware of these findings, to identifying patients at higher risk and inform interventions to reduce the risk of death. Moreover, well-designed, large-scale and multicenter studies are needed to improve and validate our findings.
\end{abstract}

Keywords SARS-COV-2 $\cdot$ COVID-19 $\cdot$ Diabetes $\cdot$ Chronic kidney disease $\cdot$ Hypertension $\cdot$ Cardiovascular disease

Seyed Alireza Dastgheib

dastgheibsa@gmail.com

1 Department of Emergency Medicine, Shahid Sadoughi University of Medical Sciences, Yazd, Iran

2 Department of Medical Genetics, School of Medicine, Shiraz University of Medical Sciences, Shiraz, Iran

3 Department of Emergency Medicine, Iran University of Medical Sciences, Tehran, Iran
4 Neonatal Research Center, Shiraz University of Medical Sciences, Shiraz, Iran

5 Mother and Newborn Health Research Center, Shahid Sadoughi University of Medical Sciences, Yazd, Iran

6 Department of Medical Genetics, Shahid Sadoughi University of Medical Sciences, Yazd, Iran

7 Department of Cardiology, Islamic Azad University, Yazd Branch, Yazd, Iran

8 Department of Food Science and Technology, School of Public Health, Shahid Sadoughi University of Medical Sciences, Yazd, Iran 


\section{Introduction}

Coronavirus disease 2019 (COVID-19) caused by 2019 novel coronavirus (2019-nCoV) has caused significant mortality and has been declared as a global pandemic by the World Health Organization [1-5]. COVID-19 is a major public health concern and one of the leading cause of mortality in most countries [6-8]. At the time this paper is written, COVID-19 has inflicted more than 55.4 million people globally and causing more than 1.3 death to date with overall mortality rate of $2.4 \%$ [9]. Based on official reports of Iran about 788,473 people infected and have surpassed 42,461 deaths up to November 17, 2020 [10]. The main reason for death due to SARS-COV-2 infection has been described and pre-existing comorbidities significantly increase the disease mortality $[11,12]$.

About $20-51 \%$ of patients hospitalized with SARS-COV2 infection are found to have at least one comorbid condition [13]. In patients with COVID-19, underlying disease such as diabetes mellitus (DM), chronic kidney disease (CKD), hypertension, cardiovascular diseases (CVDs), and other chronic diseases are associated with a higher risk of severe complications, death and may be associated with a rapid progression and poor prognosis of SARS-COV-2 infection [14-18]. To date, several clinical and epidemiological studies have indicated higher risk of SARS-COV-2 infection in DM patients $[19,20]$. However, it is not yet known whether patients with underlying DM are more susceptible to SARS-COV2 infection [21-23]. Some studies postulated that the angiotensin converting enzyme 2 (ACE2) may be the plausible explanation of the association between risk of SARS-COV2 infection in DM, CKD and CVDs patients and COVID-19 severity [24-26]. Moreover, diabetic individuals have a greater risk of respiratory infections due to compromised immune system, especially the innate immunity [27-29]. Previous studies have indicated that CKD patients with SARS-CoV-2 infection are vulnerable to be infected and become sever, since SARS-CoV-2 enters lung cells through the ACE2 receptor [30].

The link between underlying disease such as DM, CKD, hypertension and CVDs and SARS-COV-2 infection outcomes was reported in number of studies in Iran but its exact prevalence is still unclear [16, 31,32]. Moreover, the data on the risk and mortality of SARS-COV-2 infection associated with these underlying conditions are conflicting [31]. The actual burden of these underlying diseases in Iran is considerable. Understanding the relationship between risk and mortality of SARS-COV-2 infection and country of origin of these patients is an urgent research priority, in order to reduce the disproportionate burden of disease. Recently there has been an increase in the literature on clinical outcome and demographical data of SARS-COV-2 infection in Iran. However, most available data sources were based on case series or small cohorts, limiting their results. Thus, this meta-analysis was carried out to estimate the proportion and mortality of SARS-COV-2 infection among Iranian patients with DM, CKD, hypertension, and CVDs.

\section{Materials and methods}

\section{Search strategies}

We carried out a meta-analysis in accordance with the Preferred Reporting Items for Systematic Reviews and Meta-Analyses (PRISMA) guidelines (http://www. prismastatement.org). We have performed a comprehensive computer bibliographic search on PubMed/MEDLINE, Google Scholar, EMBASE, Cochrane Library database, SciELO, Springer Link, Chinese Biomedical Database (CBD), China National Knowledge Infrastructure (CNKI) platforms, VIP, Chinese literature (Wan Fang) and China Science and Technology Journal database and Egyptian Knowledge Bank (EKB) Journals to identify all relevant studies assesse the risk and mortality of SARS-CoV-2 infection in DM, CKD, hypertension and CVDs patients up to 10 January, 2020. The following medical subject headings (MeSH) terms and keywords to search: ("COVID-19 virus disease" OR "Severe Acute Respiratory Syndrome Coronavirus 2" OR "SARS-CoV-2" OR "'2019 novel coronavirus infection" OR "2019-nCoV infection" OR "'coronavirus disease" 2019 OR "'coronavirus disease-19" OR '"2019-nCoV disease" OR "COVID-19 virus infection") AND ("Death" OR "Mortality", OR "Fatal Outcome', OR "'Fatal Outcomes" OR "Outcome") AND ("Comorbidities" OR "'Underlying Disease") AND ("Diabetes Mellitus" OR "Glucose Intolerance" OR" Insulin Resistance" OR " Glucose" OR 'Blood Glucose" OR 'Blood Sugar" OR "Hyperglycemia" OR 'Hyperglycemias" OR 'Metabolic Cardiovascular Syndrome', OR 'Cardiovascular Syndrome" OR 'Metabolic Cardiovascular') AND ("Hypertension" OR 'HTN" OR 'HT', OR “ high blood pressure" OR "HBP") AND ("Chronic Kidney Disease" OR "'Renal Disease", OR "Renal Injury") AND (" Cardiovascular disease" OR "Coronary artery disease" OR "'coronary heart disease" OR "ischemic heart disease" OR " heart disease"). We restricted our search to human studies. But, there was language restriction in this meta-analysis to Persian and English language publications. In addition, we manually screened references of relevant publications and reviews for additional relevant articles. Articles included in the meta-analysis published in the primary literature and had no obvious overlap of subjects with other studies. Considering that this study was a meta-analyses and systematic review, an Institutional Review Board approval was not required. 


\section{Inclusion and exclusion criteria}

The full text of primary studies was selected according to the following inclusion and exclusion criteria: (1) primary case series and case-control publications; (2) studies evaluated clinical characteristics and outcome of SARS-CoV-2 infection Iranian patients with diabetes mellitus, chronic kidney disease, hypertension and cardiovascular disease; (3) studies reported mortality of SARS-CoV-2 infection Iranian patients with diabetes mellitus, chronic kidney disease, hypertension and cardiovascular disease; and (4) sufficient data were presented to calculate the odds ratio (OR) with $95 \%$ confidence interval (CI). In addition, the following exclusion criteria were also used: (1) insufficient data; (2) non-human or in vitro studies; (3) non-consecutive case series; (4) abstracts, case report, posters, editorials, reviews, conference papers, and previous meta-analyses and non-standard data presentation; and (5) overlapping and duplicated data.

\section{Data extraction}

Two authors independently reviewed all titles and abstracts of the selected studies in the primary search and extracted the necessary data into a standardized form. When the authors were not in agreement, a third author was involved to reach an agreement. All necessary data were extracted conforming to the standardized extraction checklist for the following data: name of first author, year of publication, city or province, mean age, study type, total numbers of infected cases and mortality, total numbers of infected cases and mortality in DM, CKD, hypertension, and CVDs patients. If a duplicate publication was found or the same population was used in multiple studies, the publication with the larger sample size was included in the meta-analysis. The corresponding author was contacted through email for any missing data.

\section{Quality score assessment}

The Newcastle-Ottawa Score (NOS) were performed to assess the quality of included studies in the meta-analysis and to assess the various aspects of the methodology used by the observational research, which are relevant to the quality of the study. This standard assessed 3 sections (selection of cases, comparability of groups, and determination of exposure) and 8 items. In the selection and exposure categories, a quality research item received $1 \mathrm{star}$, and a comparable category could receive at most 2 stars. The quality assessment values ranged from 0 stars (worst) to 9 stars (best). Thus, the studies were divided into three groups: higher quality score $\geq$ 7; moderate quality $4 \leq$ score $<7$; low quality score $<4$. Generally, the study which scored at least 5 points was considered to be included in meta-analysis and any discrepant opinions were resolved by discussion and consensus.

\section{Statistical analysis}

The proportion and mortality of SARS-COV-2 infection in Iranian patients with DM, CKD, hypertension and CVDs was assessed by odds ratios (ORs) with $95 \%$ confidence intervals (CIs). The significance of pooled ORs was determined using the $\mathrm{Z}$-test, in which $\mathrm{P}<0.05$ defined as the significance threshold. A between-study heterogeneity was tested using the Q-statistic test, which $\mathrm{P} \leq 0.10$ indicated significant heterogeneity a crossing studies. Moreover, the $\mathrm{I}^{2}$ statistic was used to qualify the heterogeneity (range of 0 to $100 \%: \mathrm{I}^{2}=0-25 \%$, no heterogeneity; $\mathrm{I}^{2}=25-50 \%$, moderate heterogeneity; $\mathrm{I}^{2}=$ 50-75\%, large heterogeneity; $\mathrm{I}^{2}=75-100 \%$, extreme heterogeneity). If between-study heterogeneity existed statistically, a random effect model (DerSimonian and Laird method) was adopted; otherwise, affixed effect model (Mantel-Haenszel method) was used in the absence of heterogeneity [33-35]. A visual inspection of the funnel plot was used to assess potential publication bias. Moreover, Egger's test was performed to assess the publication bias statistically, in which $p<0.05$ was considered statistically significant. If the publication bias tests indicated bias existed, the Duval and Tweedie "trim and fill" method was used to adjust the bias. All of the statistical calculations were performed using Comprehensive MetaAnalysis (CMA) software version 2.0 (Biostat, USA). Twosided P-values $<0.05$ were considered statistically significant.

\section{Results}

As shown in Fig. 1, a total of 528 articles were yield from the databases up to 10 January, 2020, but 287 were excluded because of duplication. Then, the titles and abstracts of the articles were checked, and 129 were excluded because they did not meet our inclusion criteria. After the full text of the articles was read, 119 were excluded due to irrelevance to the current meta-analysis scope, and/or were case reports, reviews, previous meta-analyses, and other disease or lack of the relevant data. Finally, a total of ten publication including 11,755 infected cases with 942 deaths were selected [14, 36-44]. The study characteristics of included studies in the present meta-analysis are described in Table 1. Among them, there were total of 791 DM patients with 186 deaths, 225 CKD patients with 45 deaths, 790 hypertension cases with 86 deaths, and 471 CVDs cases with 60 deaths. All included publications were retrospective case-series studies. The studies were performed in Fars, Tehran, Mazandaran and Alborz provinces. All selected studies were published in English between June 2020 and January 2021. The NOS score of the included studies was 7-9, and the quality of the articles was evaluated as high (Table 1). 


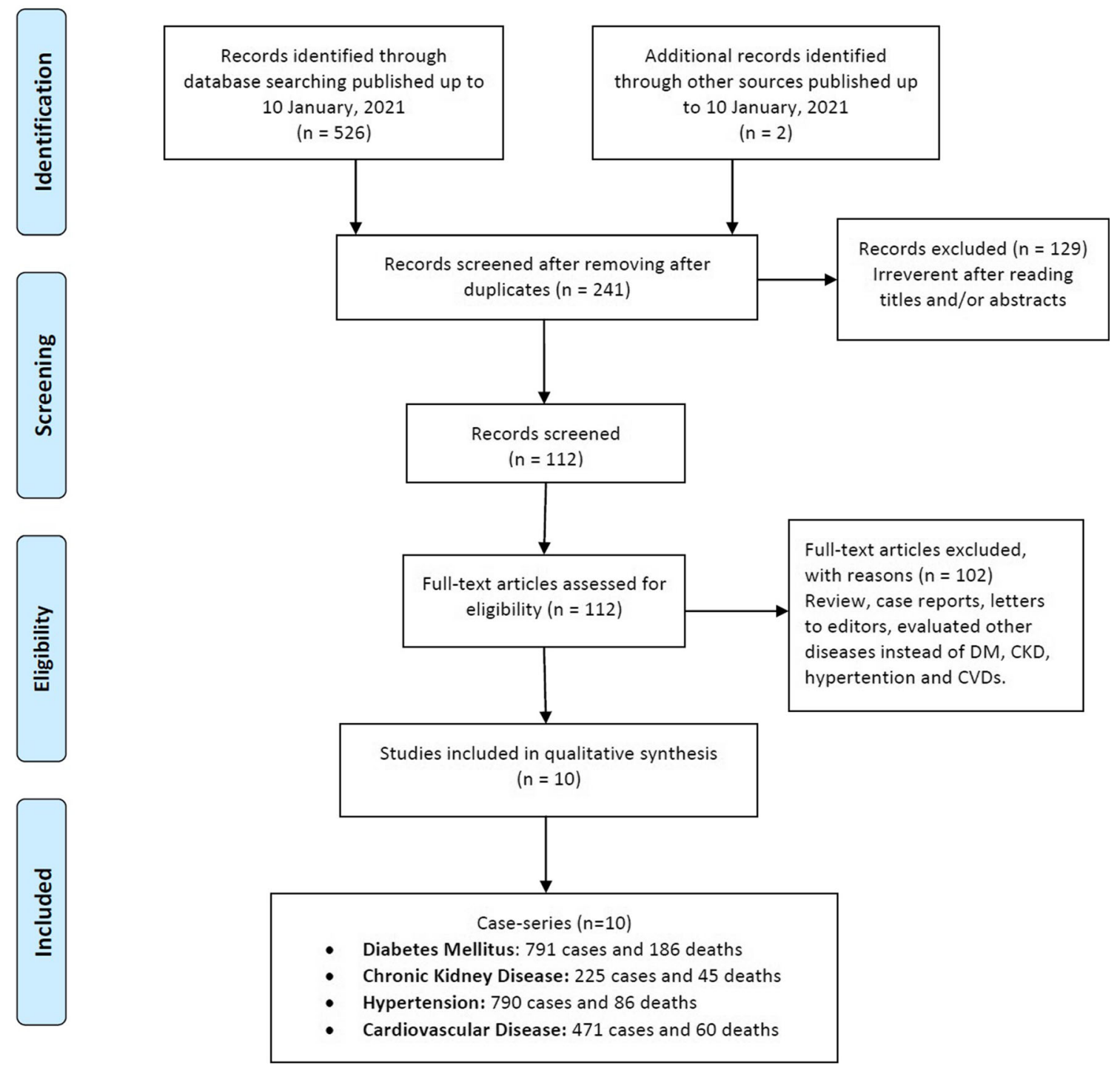

Fig. 1 The study selection and inclusion process

\section{Quantitative data synthesis}

\section{Diabetes mellitus}

The summary of proportion and mortality in the Iranian DM patients with SARS-COV-2 Infection are presented in Table 2. For the analysis of proportion of SARS-COV-2 Infection, a total of eight studies with $615 \mathrm{DM}$ patients were included. There was a significant heterogeneity, thus a random-effect meta-analysis was to estimate an OR for proportion of SARS-COV-2 Infection in DM patients. The combined results showed that the proportion of SARS-COV-2 infection in Iranian DM patients was $16.3 \%$ (95\% CI $0.085-0.291, p \leq 0.001$, Fig. 2a). For the analysis of mortality, eight studies with 132 reported deaths in DM patients were selected. A fixed-effects analysis showed a pooled ORs of 0.549 (95\% CI 0.448-0.671, $\mathrm{p} \leq 0.001$, Fig. 2b).

\section{Chronic kidney disease}

The summary of proportion and mortality in the Iranian CKD patients with SARS-COV-2 Infection are presented in Table 2. For the analysis of proportion of SARS-COV2 Infection, a total of seven studies with 195 CKD patients were included. There was a significant heterogeneity, thus a random-effect meta-analysis was to estimate an OR for risk of infection in CKD patients. Pooled data showed that the proportion of SARS-COV-2 Infection in the CKD patients was $5.0 \%(95 \%$ CI $0.019-0.124, \mathrm{p} \leq$ 0.001 , Fig. 3a). For the analysis of mortality, six studies with 39 deaths in CKD patients were included. A fixedeffects analysis showed a pooled ORs of 0.552 (95\% CI 0.367-0.829, $\mathrm{p}=0.004$, Fig. 3b). 


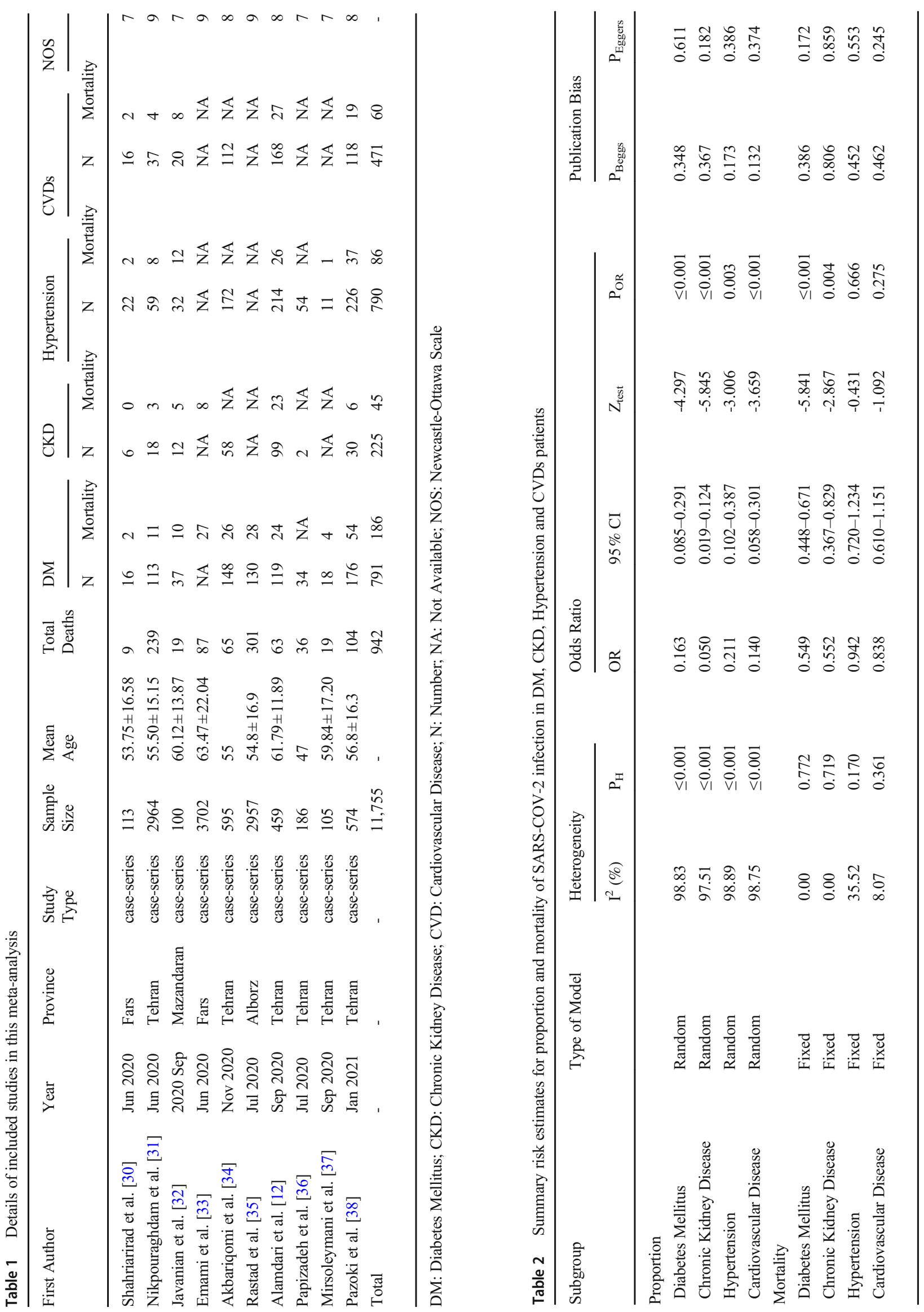


a

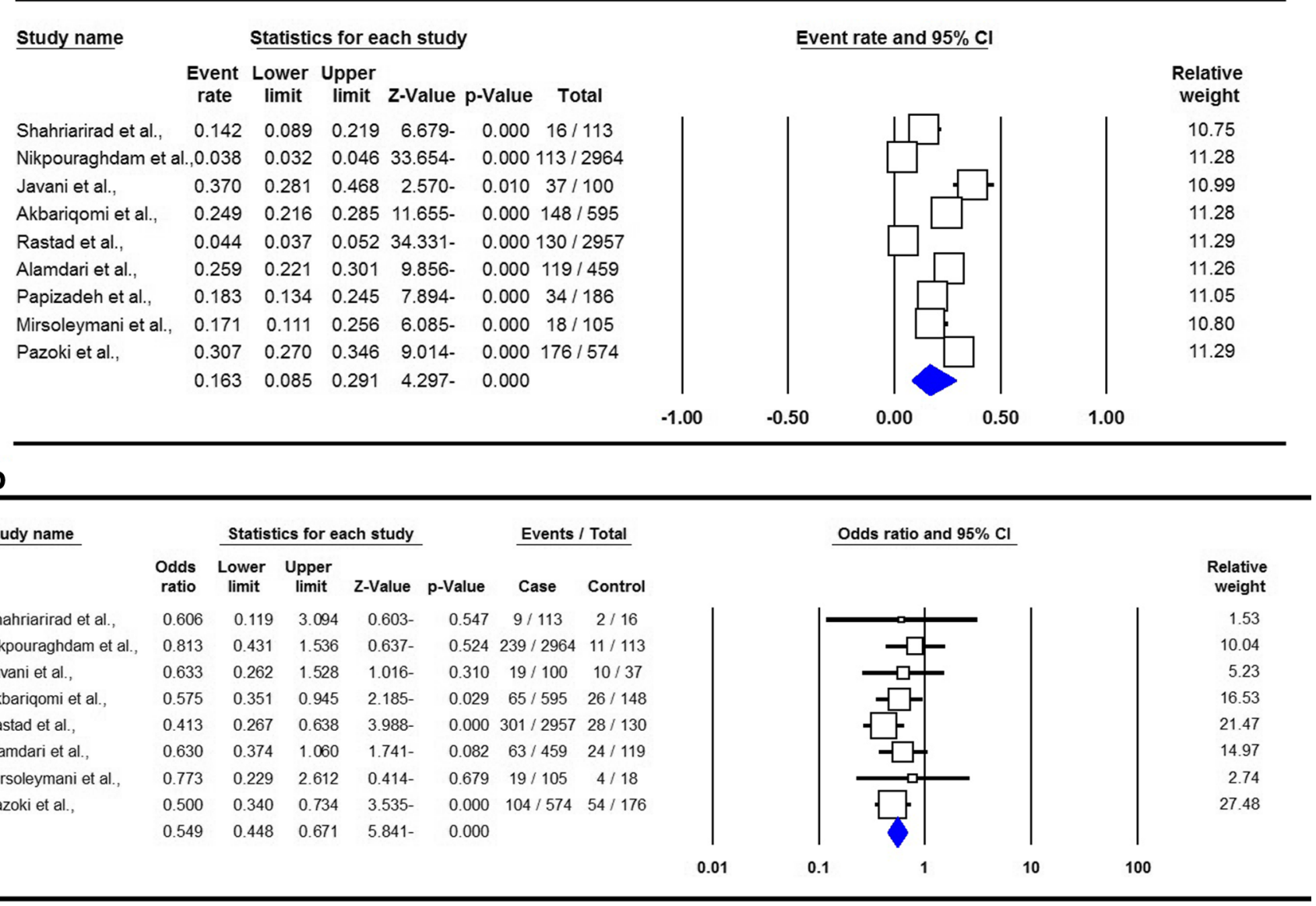

Fig. 2 Forest plots for proportion (a) and mortality (b) in the Iranian diabetes mellitus patients with SARS-COV-2 Infection

\section{Hypertension}

The summary of proportion and mortality in the Iranian hypertension patients with SARS-COV-2 Infection are presented in Table 2. For the analysis of proportion of SARS-COV-2 Infection, a total of eight studies with 564 cases with hypertension were included. There was a significant heterogeneity, thus a random-effect meta-analysis was to estimate an OR for proportion of infection in hypertension patients. Pooled data revealed that the proportion of SARS-COV-2 Infection in the hypertension patients was $21.1 \%$ (95\% CI 0.102-0.387, p= 0.003 , Fig. $4 \mathrm{a}$ ). For the analysis of mortality, six studies with 49 deaths in patients with hypertension were selected. A fixed-effects analysis showed a pooled ORs of $0.942(95 \%$ CI $0.720-1.234, \mathrm{p}=0.666$, Fig. 4b).

\section{Cardiovascular disease}

The summary of proportion and mortality in the Iranian CVDs patients with SARS-COV-2 Infection are presented in
Table 2. For assessment of proportion of SARS-COV2 infection in CVD patients, a total of eight studies with 353 cases with CVD were included. There was a significant heterogeneity, thus a random-effect meta-analysis was to estimate an OR for proportion of infection in hypertension patients. Pooled data revealed that the proportion of SARSCOV-2 Infection in the CVD patients was $14.0 \%(95 \% \mathrm{CI}$ $0.058-0.301, \leq 0.001$, Fig. $5 a$ ). For the analysis of mortality, six studies with 41 deaths in patients with CVD were selected. A fixed-effects analysis showed a pooled ORs of $0.838(95 \%$ CI $0.610-1.151, \mathrm{p}=0.275$, Fig. 5b).

\section{Heterogeneity test}

Table 2 listed the main results of between-study heterogeneity for proportion and mortality in the infected patients with COVID-19. The analyses provide an important visualization of the data available, and highlight the between-study heterogeneity for proportion in the Iranian patients with DM $\left(\mathrm{I}^{2}=\right.$ 98.83, $\left.\mathrm{P}_{\mathrm{h}} \leq 0.001\right), \mathrm{CKD}\left(\mathrm{I}^{2}=97.51, \mathrm{P}_{\mathrm{h}} \leq 0.001\right)$, hypertension 
a

\begin{tabular}{|c|c|c|c|c|c|c|}
\hline \multirow[t]{2}{*}{ Study name } & \multicolumn{6}{|c|}{ Statistics for each study } \\
\hline & $\begin{array}{c}\text { Event } \\
\text { rate }\end{array}$ & $\begin{array}{l}\text { Lower } \\
\text { limit }\end{array}$ & $\begin{array}{l}\text { Upper } \\
\text { limit }\end{array}$ & Z-Value & p-Value & Total \\
\hline Shahriarirad et al., & 0.053 & 0.024 & 0.113 & $6.867-$ & 0.000 & $6 / 113$ \\
\hline Nikpouraghdam et al & $1 ., 0.006$ & 0.004 & 0.010 & $21.562-$ & 0.000 & $18 / 2964$ \\
\hline Javani et al., & 0.120 & 0.069 & 0.200 & 6.475 & 0.000 & $12 / 100$ \\
\hline Akbariqomi et al., & 0.097 & 0.076 & 0.124 & $16.102-$ & 0.000 & $58 / 595$ \\
\hline Alamdari et al., & 0.216 & 0.180 & 0.256 & 11.376- & 0.000 & $99 / 459$ \\
\hline Papizadeh et al., & 0.011 & 0.003 & 0.042 & $6.360-$ & 0.000 & $2 / 186$ \\
\hline Pazoki et al., & 0.052 & 0.037 & 0.074 & $15.451-$ & 0.000 & $30 / 574$ \\
\hline
\end{tabular}

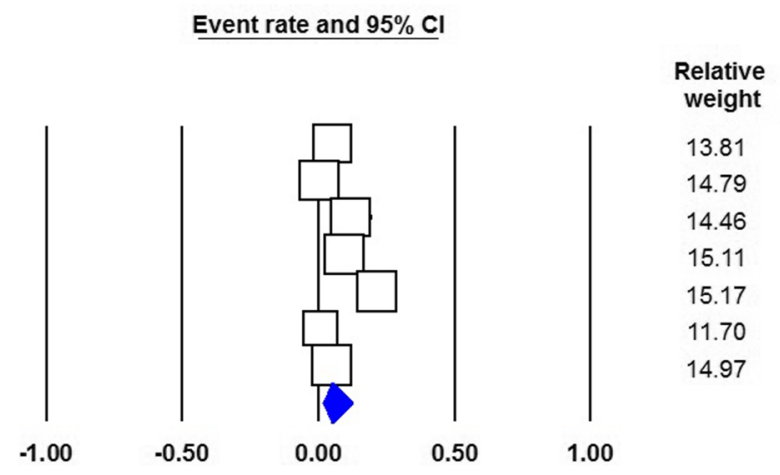

b

\begin{tabular}{|c|c|c|c|c|c|c|c|}
\hline \multirow[t]{2}{*}{ Study name } & \multicolumn{4}{|c|}{ Statistics for each study } & \multicolumn{3}{|c|}{ Events / Total } \\
\hline & $\begin{array}{l}\text { Odds } \\
\text { ratio }\end{array}$ & $\begin{array}{c}\text { Lower } \\
\text { limit }\end{array}$ & $\begin{array}{c}\text { Upper } \\
\text { limit }\end{array}$ & Z-Value & p-Value & Case & Control \\
\hline Shahriarirad et al., & 1.182 & 0.062 & 22.628 & 0.111 & 0.912 & $9 / 113$ & $0 / 6$ \\
\hline Nikpouraghdam et al., & 0.439 & 0.126 & 1.525 & $1.296-$ & 0.195 & 239 / 2964 & $3 / 18$ \\
\hline Javani et al., & 0.328 & 0.094 & 1.148 & $1.744-$ & 0.081 & $19 / 100$ & $5 / 12$ \\
\hline Alamdari et al., & 0.526 & 0.307 & 0.899 & $2.348-$ & 0.019 & $63 / 459$ & $23 / 99$ \\
\hline \multirow[t]{2}{*}{ Pazoki et al., } & 0.885 & 0.353 & 2.220 & 0.260 & 0.795 & $104 / 574$ & $6 / 30$ \\
\hline & 0.552 & 0.367 & 0.829 & $2.867-$ & 0.004 & & \\
\hline
\end{tabular}
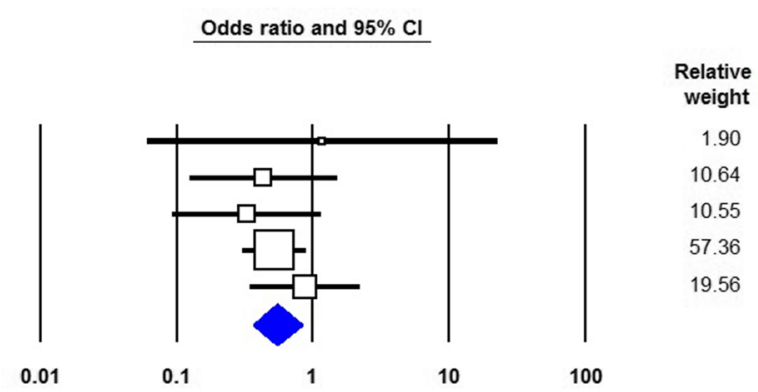

Fig. 3 Forest plots for proportion (a) and mortality (b) in the Iranian chronic kidney disease patients with SARS-COV-2 Infection

$\left(\mathrm{I}^{2}=98.89, \mathrm{P}_{\mathrm{h}} \leq 0.001\right)$ and CVDs $\left(\mathrm{I}^{2}=98.75, \mathrm{P}_{\mathrm{h}} \leq 0.001\right)$. However, there was no significant heterogeneity for mortality in the patients with SARS-COV-2 infection. Thus, need to improve data collection and analysis, including greater standardization in adjusted analyses. The heterogeneity in whole population and subgroups was shown in Table 2.

\section{Sensitivity analysis}

A sensitivity analysis is an important part of a meta-analysis to evaluate the robustness of the pooled data to the assumptions made in performing the analysis [45]. Thus, we performed sensitivity analysis of the summary ORs by sequential removal of each study to assess the stability of our findings. Results revealed that none of the studies changed the pooled OR for proportion and mortality in Iranian DM, CKD, hypertension, and CVDs patients with SARS-COV-2 Infection. Taken together, these results suggested that the our findings were robust and stable.

\section{Publication bias}

The most commonly used method to evaluate a dataset for potential publication bias in a meta-analysis is via the construction of funnel plots [45]. We performed Funnel plot and Egger's linear regression test to detect publication bias. The shapes of the funnel plots did not reveal evidence of obvious asymmetry in all comparison models. Moreover, the Egger's test was used to provide statistical evidence of publication funnel plot symmetry. No obvious evidence of publication bias was revealed by the results (Table 2). Figure 4 showed the funnel plots for proportion (Fig. 6a-d) and mortality (Fig. $7 \mathrm{a}-\mathrm{d}$ ) of SARS-COV-2 infection in Iranian patients with diabetes mellitus, chronic kidney disease and hypertension, respectively.

\section{Discussion}

Several previous single studies and meta-analyses indicated that DM, CKD, hypertension and CVD might be risk factor and promoter of severity and mortality for SARS-COV2 infection [26]. It is possible that mechanism mediated by ACE2 receptor links patients with these underlying diseases with a higher risk of SARS-COV-2 infection and death [31, 46, 47]. To date, some studies evaluated the proportion and mortality of SARS-COV-2 infection in the Iranian DM, CKD, hypertension and CVD patients. To our knowledge, this is the first meta-analysis to assess the proportion and mortality of SARS-COV-2 infection in the Iranian DM, CKD, hypertension and CVD patients. Our combined data based on ten studies with 11,755 infected cases and 942 deaths showed that the 
a

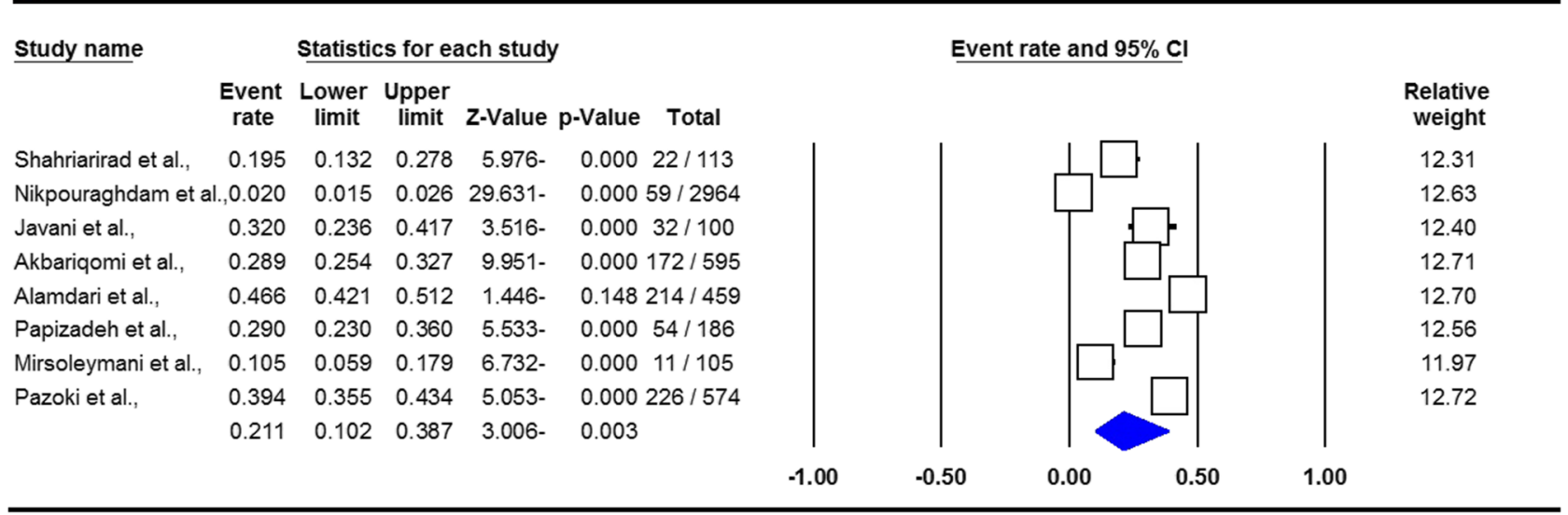

b

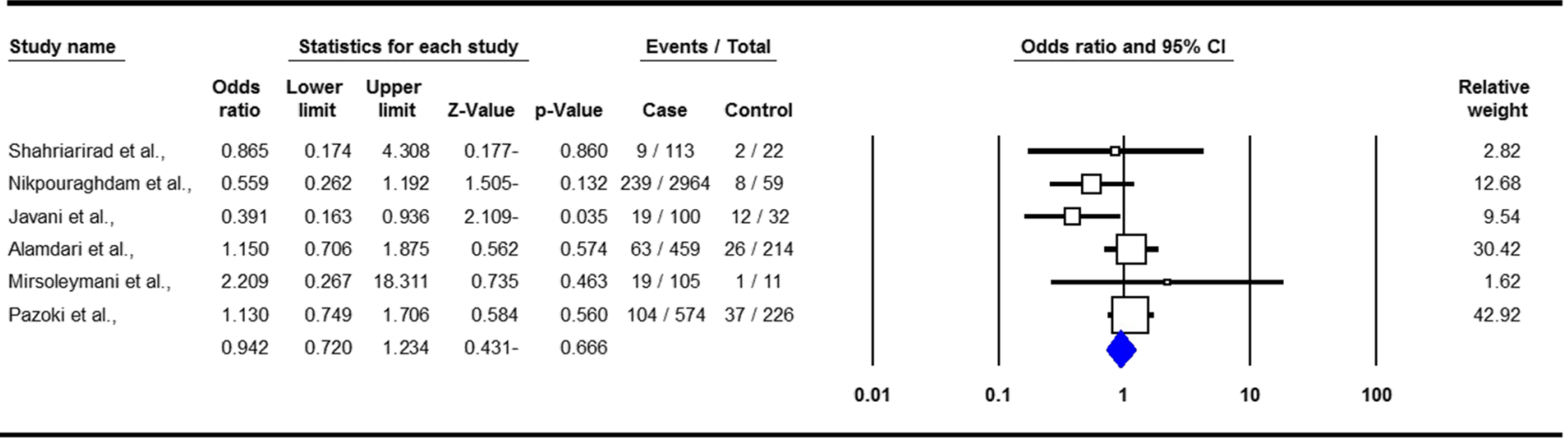

Fig. 4 Forest plots for proportion (a) and mortality (b) in the Iranian hypertension patients with SARS-COV-2 Infection

proportion of SARS-COV-2 infection in the Iranian DM, CKD, hypertension and CVD patients were $21.1 \%, 16.3 \%, 14.0 \%$ and $5.0 \%$, respectively. Moreover, the pooled ORs revealed that there was significant correlation between mortality and SARSCOV-2 infection in the Iranian DM and CKD patients.

The link between risk and COVID-19 outcomes and SARS-COV-2, Severe Acute Respiratory Syndrome (SARS$\mathrm{CoV}$ ) and Middle East Respiratory Syndrome (MERS-Cov) infection was previously reported in single studies and metaanalyses worldwide [21, 48, 49]. It is well known that allcause mortality rate in patients with DM is higher than in patients without DM [50-52]. Our pooled data showed that the proportion of SARS-COV-2 infection in the Iranian patients with DM was $16.3 \%$. Moreover, our findings showed that the SARS-COV-2 infection was associated with an increased risk of mortality in the DM patients. We found a 0.549 -fold increase in mortality associated with SARSCOV-2 infection in Iranian patients with DM (Table 2). de Almeida-Pititto et al., in a meta-analysis with a total of 4305 cases with $564 \mathrm{DM}$ demonstrated a 2.3 -fold increase in the risk of severity and a 2.5 -fold increase in mortality associated with SARS-COV-2 infection in those patients worldwide [31]. Huang et al., in a meta-analysis of 30 studies with 6452 patients revealed that the DM was associated with poor outcome of the COVID-19. Their results showed that DM was associated with higher mortality rate in in patients with COVID-19 pneumonia. However, DM was not associated with increased need for ICU care [53]. Moreover, Kumar et al., in a meta-analysis of 33 studies (16,003 cases) found a 1.90 -fold increase for DM mortality among people with SARS-COV-2 infection [32]. Barron et al., in nationwide analysis in England in patients with SARS-COV-2 infection between March 1 and May 11, 2020 reported that patients with DM was associated with significantly increased ORs of in-hospital death with COVID-19. Moreover, their results revealed that DM status, age, gender, ethnicity, and deprivation were potential confounding factors in the mortality of those patients [54]. Singh et al., in a meta-analysis based on 18 studies with 14,558 cases reported that the pooled prevalence for comorbidities in patients with COVID-19 disease was $10 \%$ for CVDs, $11 \%$ for DM, and $23 \%$ for hypertension. They described that CVDs, DM and hypertension significantly increased the risk of severe COVID-19 [18]. Barron et al., revealed that DM patients with COVID-19 had 3.5 and 2.0 times higher mortality in hospital compared to those without $\mathrm{DM}$, and this was attenuated to 2.9 and 1.8 when adjusted for previous hospital admissions with coronary heart disease, cerebrovascular disease or heart failure in UK [54]. 
a

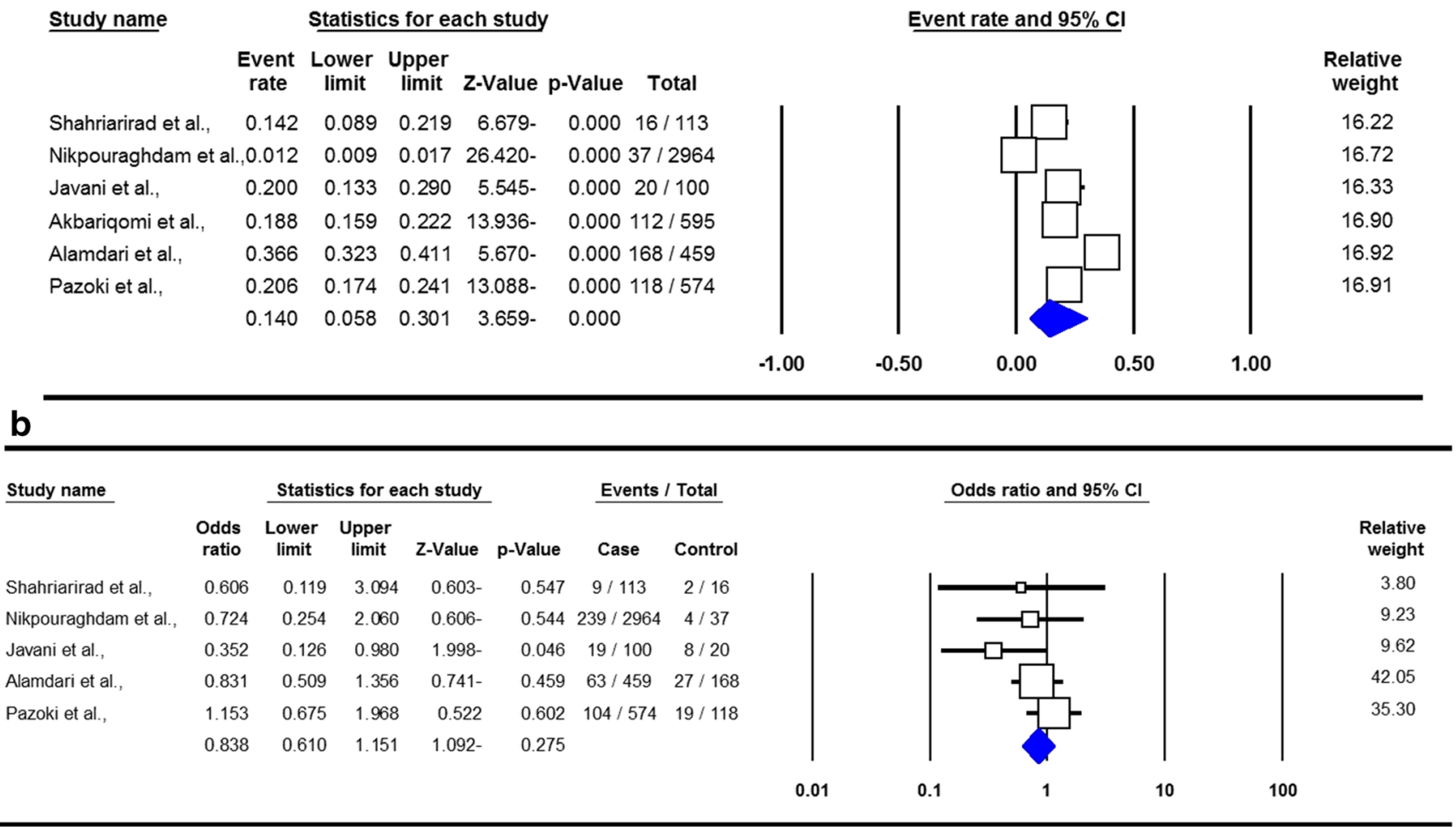

Fig. 5 Forest plots for proportion (a) and mortality (b) in the Iranian cardiovascular disease patients with SARS-COV-2 Infection

Previous studies have described that there is the involvement of kidneys with SARS-COV-2 infection which might be caused high mortality $[55,56]$. It has been suggested that CKD in patients with SARS-COV-2 infection might be caused by synergistic effect of virus-induced direct cytotropic effect and cytokine-induced systemic inflammatory response [57]. In the current meta-analysis, the proportion of SARSCOV-2 infection in the Iranian patients with DM was $16.3 \%$. Moreover, our findings showed that the SARS-COV2 infection was associated with an increased risk of mortality in the CKD patients. Moreover, it was associated with 0.552fold increase of mortality among Iranian infected patients with SARS-COV-2 (Table 2). Cai et al., in a meta-analysis based 12 studies with 3,867,367 cases described that the mortality rate among CKD patients with SARS-COV-2 infection was significantly higher that CKD patients without SARS-COV2 infection $(\mathrm{OR}=5.81 ; 95 \%$ CI $3.78-8.94, \mathrm{P} \leq 0.001)$. They suggested that the major reason is that the levels of proinflammatory cytokines are increased in the CKD infected patients and leads to an increase in oxidative stress that eventually produces an inflammatory immune response [58]. Moreover, they have shown that CKD was significantly associated with an increased risk of mortality in elderly $(\leq 70)$ infected patients. Kolhe et el., in a study among 1,161 UK infected with COVID-19 patients showed a high incidence of acute kidney injury (AKI) in patients with SARS-COV2 infection which is associated with a 3 fold higher ORs of mortality than infected patients without AKI and a 4-fold higher odds of death than AKI due to other causes [55].

It appears that hypertension is a risk factor for severe form of SARS-COV-2 infection [59]. CVDs are frequent in SARSCOV-2 infection, and might contribute to severe forms of COVID-19 and mortality [60]. However, the mechanism implicated in the association between severity or mortality of SARS-COV-2 infection and CVD is still under investigation. Potential explanations include the high prevalence of cardiovascular disease in older people (another established risk factor for adverse outcome), a functionally impaired immune system, and an elevated angiotensin converting enzyme-2 (ACE2) receptor expression. Our pooled ORs revealed that the proportion of SARS-COV-2 infection in Iranian patients with CVDs was $14.0 \%$, respectively. However, there was no significant association between mortality in the patients with CVDs and COVID-19 (Table 2). Hessami et al., in a metaanalysis including 159,698 COVID-19 patients reported a high burden of CVDs in patients with SARS-COV-2 infection, which was significantly associated with mortality and ICU admission [61]. Moreover, in the current meta-analysis, we found that the proportion of SARS-COV-2 infection in Iranian patients with hypertension was $21.1 \%$. However, pooled data revealed that the SARS-COV-2 infection was not associated with an increased risk of mortality in the hypertension patients (Table 2). A study revealed a significantly increased risk of adverse outcomes in CVDs patients with 

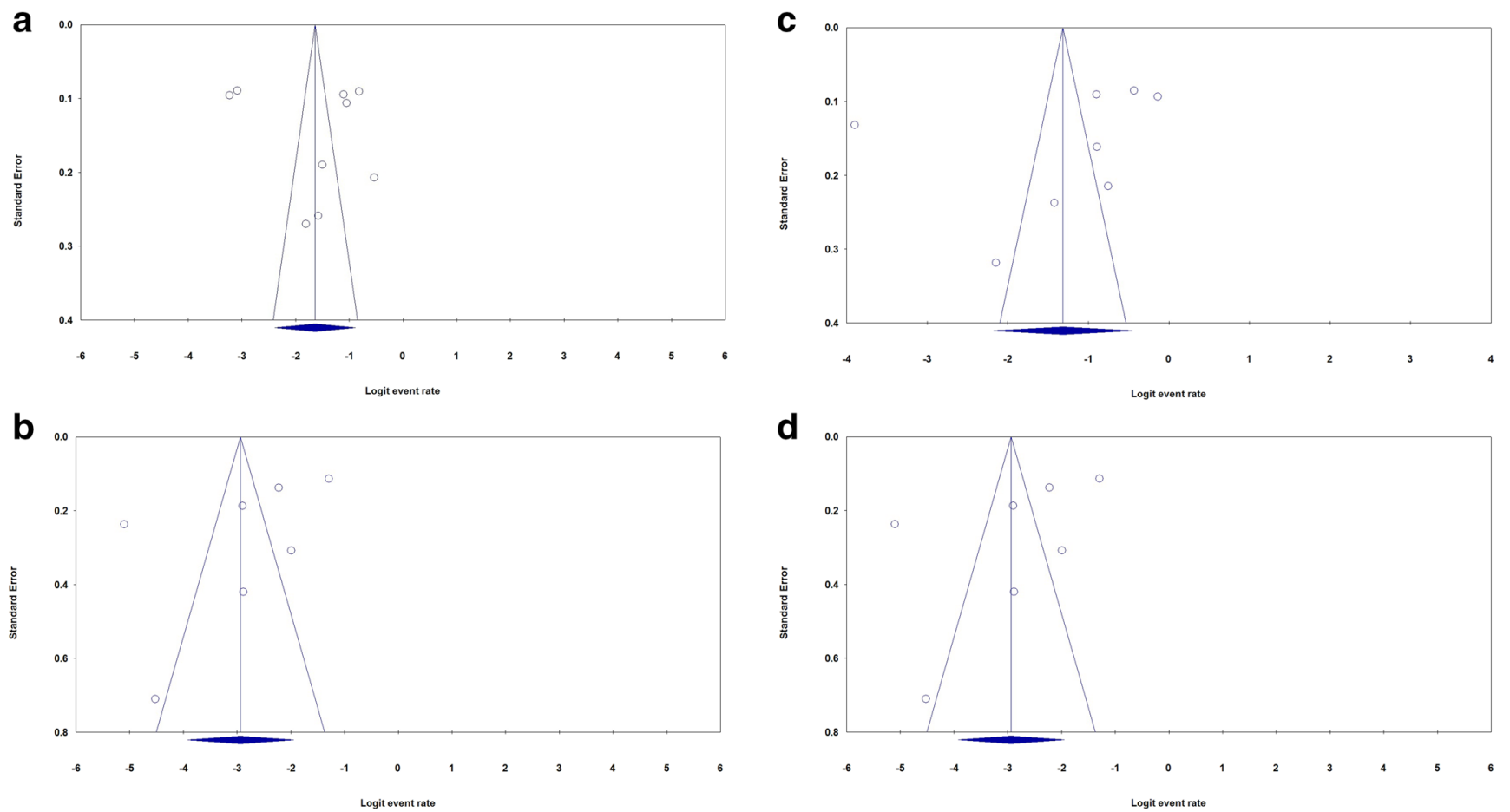

Fig. 6 Begg's funnel plot for publication bias test for proportion of SARS-COV-2 infection in Iranian patients with diabetes mellitus (a), chronic kidney disease (b), hypertension (c) and cardiovascular disease (d)

15 to $70 \%$ of COVID-19 related deaths [62]. However, a previous meta-analysis described that COVID-19 has a higher mortality and case fatality rate and has increased risk of adverse outcomes in patients with underlying CVDs [62]. Singh

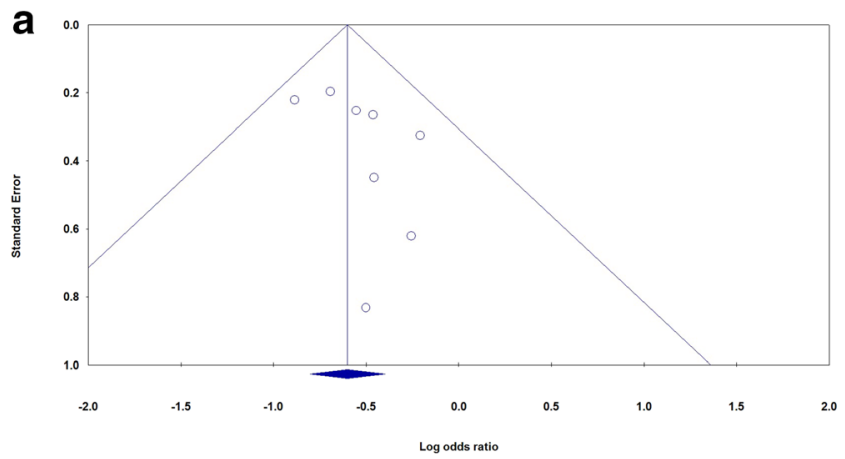

b

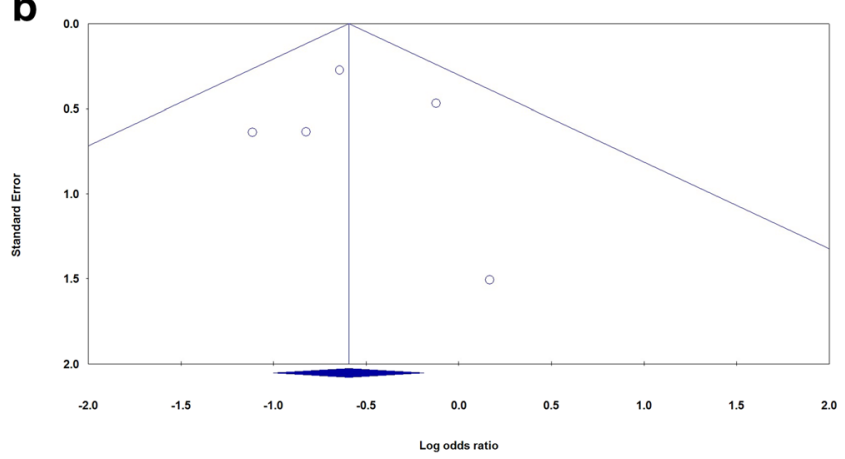

et al., in a meta-analysis revealed that the CVDS increased the risk of mortality in patients SARS-COV-2 infection [18]. A study in Hubei province among 44672 confirmed cases with COVID-19 reported that infected patients without any
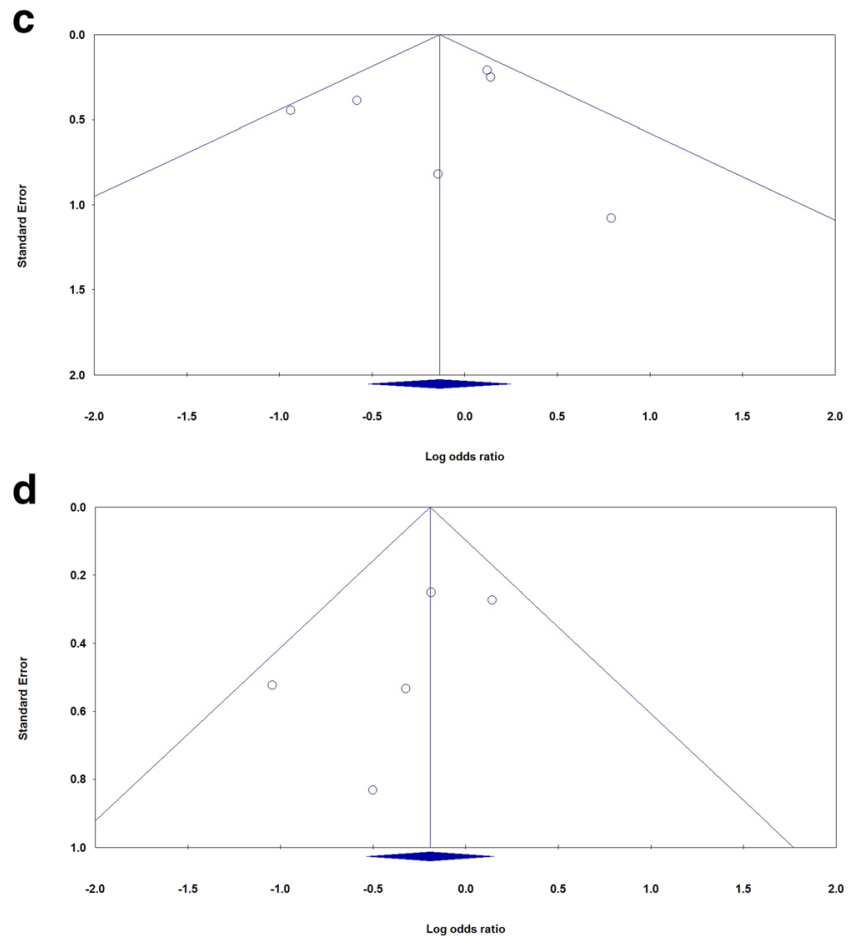

Fig. 7 Begg's funnel plot for publication bias test for mortality of SARS-COV-2 infection in Iranian patients with diabetes mellitus (a), chronic kidney disease (b), hypertension (c) and cardiovascular disease (d) 
underling disease had a case fatality rate of $0.9 \%$, rising to $6 \%$ in patients with hypertension, $7 \%$ in patients with diabetes and $10 \%$ in patients with CVDs [63]. Momtamanesh et al., in meta-analysis based on 35 studies revealed that CVDs occurred in more than $25 \%$ of infected cases with SARS-COV2 , mortality was 20 times higher, and admission to ICU increased by 13.5 times. They have demonstrated that CVDs are common in patients with SARS-COV-2 infection and are associated with increased severity and mortality in these patients [64]. We suggested that these patients might have used ACE inhibitors and ARBs which reduced mortality of SARS-COV2 infection. Hippisley-Cox et al., revealed that ACE inhibitors were associated with a significantly reduced risk of SARSCOV-2 infection requiring hospital admission, but were not significantly associated with risk of ICU care [65]. Previous studies indicated that the association between hypertension and worse outcomes of SARS-COV-2 Infection may be due to the higher proportion of comorbidities and a more advanced age of these patients. Pranata et al., in a meta-analysis revealed that hypertension was associated with increased mortality and COVID-19 severity [31]. However, Iccarino et al., reported that hypertension was not an independent factor affecting the SARS-COV-2 Infection in Italian patients [66].

It should be noted that the current meta-analysis has some limitation which should be considered. First, all included articles included in this study published in English-language journals, which might lead to language bias and studies issued in other languages and unpublished studies might be missed. Second, the numbers of studies as well as sample sizes in some studies were relatively limited, which Type-II error might not be dismissed and influenced reliability of this meta-analysis findings. Third, a study included in the current meta-analysis involved data that had not been peer reviewed. However, inclusion of preprint studies helped to provide a broader views of the emerging literature, in a rapidly evolving field. Fourth, the current meta-analysis was performed in Iranian patients, which may have led to the selection bias. Moreover, these results cannot be generalized to other populations. Fifth, the small number of only ten studies indicated that the statistical power to detect differences was suboptimal. However, the pooled results in our review were more reliable than the results in each of the individual studies. Finally, multivariate analysis for adjusting the several confounding factors such as age and gender that could have an effect on results was not performed due to insufficient data in most studies. Thus, a more precise analysis stratified by clinical manifestation would require further evaluation.

In summary, this study presents a literature review and meta-analysis of the information reported so far on the proportion and mortality rate of Iranian DM, CKD, hypertension, and CVDs patients with SARS-COV-2 infection. Our pooled data revealed that the proportion of SARS-COV-2 infection was the highest in the Iranian patients with hypertension
(21.1\%) followed by DM (16.3\%), CVDs (14.0\%) and CKD (5.0\%). Moreover, DM and CKD in the Iranian patients with SARS-COV-2 infection were associated with a 0.549 and 0.552 -fold increase in mortality, respectively. Clinicians in Iran should be aware of these findings, to identify patients at higher risk and inform interventions to reduce the risk of death. However, multicenter and well-designed studies with larger sample size are needed to improve our findings and to provide a higher level of evidence.

Acknowledgements The authors thank the editors and the anonymous reviewers for insightful suggestions on this study.

Author contributions Hamid Mirjalili and Seyed Alireza Dastgheib: conceptualization, investigation.

Seyed Hossein Shaker and Seyed Mohamad Hossein Sadr-Bafghi: investigation.

Jalal Sadeghizadeh-Yazdi, Reza Bahrami, Mahta Mazaheri: Investigation, writing.

Seyed Alireza Dastgheib and Hossein Neamatzadeh: Methodology, software, formal analysis.

Seyed Alireza Dastgheib: Formal analysis.

Mahta Mazaheri: Project administration.

Hossein Neamatzadeh, Hamid Mirjalili and Jalal SadeghizadehYazdi: Writing, reviewing, editing.

Funding Not applicable.

Data availability The datasets generated during and/or analyzed during this study are the corresponding author on reasonable request.

\section{Declarations}

Conflicts of interest/Competing interests The authors declare that they have no conflict of interest.

Ethics approval This article does not contain any studies with human participants or animals performed by any of the authors.

Consent to participate Not applicable for this manuscript.

Ethics approval This article does not contain any studies with human participants or animals performed by any of the authors.

\section{References}

1. Karimi-Zarchi M, Neamatzadeh H, Dastgheib SA, Abbasi H, Mirjalili SR, Behforouz A, et al. Vertical transmission of coronavirus disease 19 (COVID-19) from infected pregnant mothers to neonates: a review. Fetal Pediatr Pathol. 2020;39:246-50.

2. Jarahzadeh HM, Asadian F, Farbod M, Meibodi B, Abbasi H, Jafari $\mathrm{M}$, et al. Cancer and coronavirus disease (COVID-19): Comorbidity, mechanical ventilation, and death risk. J Gastrointest Cancer. 2020;1-5. https://doi.org/10.1007/s12029020-00529-2.

3. Antikchi MH, Neamatzadeh H, Ghelmani Y, Jafari-Nedooshan J, Dastgheib SA, Kargar S, et al. The risk and prevalence of COVID19 infection in colorectal cancer patients: a systematic review and 
meta-analysis. J Gastrointest Cancer. 2020;1-7. https://doi.org/10. 1007/s12029-020-00528-3.

4. Akbari H, Tabrizi R, Lankarani KB, Aria H, Vakili S, Asadian F, et al. The role of cytokine profile and lymphocyte subsets in the severity of coronavirus disease 2019 (COVID-19): A systematic review and meta-analysis. Life Sci. 2020;258:118167.

5. Noorishadkam M, Lookzadeh MH, Mazaheri M, Mirjalili SR, Bahrami R, Asadian F, et al. Coronavirus disease 2019 (COVID19 ) and late pregnancy loss in infected pregnant women: a mini review. World J Peri Neonatol. 2020;2:67-70.

6. Sachs JD, Abdool Karim S, Aknin L, Allen J, Brosbøl K, Cuevas Barron G, et al. Lancet COVID-19 commission statement on the occasion of the 75th session of the UN General Assembly. Lancet. 2020;396:1102-24.

7. Kontis V, Bennett JE, Rashid T, Parks RM, Pearson-Stuttard J, Guillot M, et al. Magnitude, demographics and dynamics of the effect of the first wave of the COVID-19 pandemic on all-cause mortality in 21 industrialized countries. Nat Med. 2020;26:191928.

8. Schwartz DA, Dhaliwal A. Infections in pregnancy with Covid-19 and other respiratory RNA virus diseases are rarely, if ever, transmitted to the fetus: Experiences with coronaviruses, parainfluenza, metapneumovirus respiratory syncytial virus, and influenza. Arch Pathol Lab Med. 2020;144:920-8.

9. Coronavirus Update (Live): 91,459,410 Cases and 1,956,575 Deaths from COVID-19 Virus Pandemic - Worldometer [Internet]. [cited 2021 Jan 12]. Available from: https://www. worldometers.info/coronavirus/?

10. Coronavirus Update (Live): 55,427,464 Cases and 1,333,750 Deaths from COVID-19 Virus Pandemic - Worldometer [Internet]. [cited 2020 Nov 17]. Available from: https://www. worldometers.info/coronavirus/?

11. Javanmardi F, Keshavarzi A, Akbari A, Emami A, Pirbonyeh N. Prevalence of underlying diseases in died cases of COVID-19: A systematic review and meta-analysis. PLoS One. 2020;15: e0241265.

12. Sanyaolu A, Okorie C, Marinkovic A, Patidar R, Younis K, Desai $\mathrm{P}$, et al. Comorbidity and its impact on patients with COVID-19. SN Compr Clin Med. 2020;2:1069-76.

13. Hussain S, Baxi H, Chand Jamali M, Nisar N, Hussain MS. Burden of diabetes mellitus and its impact on COVID-19 patients: A metaanalysis of real-world evidence. Diabetes Metab Syndr Clin Res Rev. 2020;14:1595-602.

14. Alamdari NM, Afaghi S, Rahimi FS, Tarki FE, Tavana S, Zali A, et al. Mortality risk factors among hospitalized COVID-19 patients in a major referral center in Iran. Tohoku J Exp Med. 2020;252:7384.

15. Jesú Puchades M, Romero-Parra M, Gimenez-Civera E, José Soler M, Ortiz A, Luis Gorriz J, et al. Coronavirus disease 2019 in chronic kidney disease. Clin Kidney J. 2020;13:297-306.

16. Bajgain KT, Badal S, Bajgain BB, Santana MJ. Prevalence of comorbidities among individuals with COVID-19: A rapid review of current literature. Am J Infect Control. 2020;S0196-6553:30637-4.

17. Buffet L, Ricchetti C. Chronic kidney disease and hypertension: A destructive combination. US Pharm. 2012;37:26-9.

18. Singh AK, Gillies CL, Singh R, Singh A, Chudasama Y, Coles B, et al. Prevalence of co-morbidities and their association with mortality in patients with COVID-19: A systematic review and metaanalysis. Diabetes Obes Metab. 2020;22:1915-24.

19. Erener S. Diabetes, infection risk and COVID-19. Mol Metab. 2020;39:101044.

20. Pugliese G, Vitale M, Resi V, Orsi E. Is diabetes mellitus a risk factor for COronaVIrus Disease 19 (COVID-19)? Acta Diabetol. 2020;57(11):1275-85. https://doi.org/10.1007/s00592020-01586-6.
21. Deravi N, Fathi M, Vakili K, Yaghoobpoor S, Pirzadeh M, Mokhtari M, et al. Systematic review SARS-CoV-2 infection in patients with diabetes mellitus and hypertension: a systematic review. Rev Cardiovasc Med. 2020;21:385-97.

22. Roy S, Mazumder T, Banik S. The association of cardiovascular diseases and diabetes mellitus with COVID-19 (SARS-CoV-2) and their possible mechanisms. SN Compr Clin Med. 2020;2:1077-82.

23. Williams DM, Nawaz A, Evans M. Diabetes and novel coronavirus infection: implications for treatment. Diabetes Ther. 2020;11:191524.

24. Filardi T, Morano S. COVID-19: is there a link between the course of infection and pharmacological agents in diabetes? J Endocrinol Investig Springer. 2020;43:1053-60.

25. Chung MK, Karnik S, Saef J, Bergmann C, Barnard J, Lederman MM, et al. SARS-CoV-2 and ACE2: The biology and clinical data settling the ARB and ACEI controversy. EBioMedicine. 2020;58: 102907.

26. Valencia I, Peiró C, Lorenzo Ó, Sánchez-Ferrer CF, Eckel J, Romacho T. DPP4 and ACE2 in diabetes and COVID-19: therapeutic targets for cardiovascular complications? Front Pharmacol. 2020;11:1161.

27. Milionis C, Milioni SO. A brief analysis and hypotheses about the risk of COVID-19 for people with type 1 and type 2 diabetes mellitus. J Diabetes Metab Disord. 2020;19(2):1-5. https://doi. org/10.1007/s40200-020-00592-3.

28. Apicella M, Campopiano MC, Mantuano M, Mazoni L, Coppelli A, Del Prato S. COVID-19 in people with diabetes: understanding the reasons for worse outcomes. Lancet Diabetes Endocrinol. 2020;8:782-92.

29. Kurts C, Panzer U, Anders H-J, Rees AJ. The immune system and kidney disease: basic concepts and clinical implications. Nat Rev Immunol. 2013;13:738-53.

30. Hardenberg JB, Luft FC. Covid-19, ACE2 and the kidney. Acta Physiol. 2020;230:e13539.

31. De Almeida-Pititto B, Dualib PM, Zajdenverg L, Dantas JR, De Souza FD, Rodacki M, et al. Severity and mortality of COVID 19 in patients with diabetes, hypertension and cardiovascular disease: A meta-analysis. Diabetol Metab Syndr. 2020;12:75.

32. Kumar A, Arora A, Sharma P, Anikhindi SA, Bansal N, Singla V, et al. Is diabetes mellitus associated with mortality and severity of COVID-19? A meta-analysis. Diabetes Metab Syndr Clin Res Rev. 2020;14:535-45.

33. Bahrami R, Dastgheib SA, Niktabar SM, Amooee A, Lookzadeh MH, Mirjalili SR, et al. Association of BMP4 rs17563 polymorphism with nonsyndromic cleft lip with or without cleft palate risk: literature review and comprehensive meta-analysis. Fetal Pediatr Pathol. 2020;1-15. https://doi.org/10.1080/15513815.2019. 1707916. Online ahead of print.

34. Mousavi A, Karimi-Zarchi M, Modares Gilani M, Behtash N, Ghaemmaghami F, Shams M, et al. Radical hysterectomy in the elderly. World J Surg Oncol. 2008;6:38. https://doi.org/10.1186/ 1477-7819-6-38.

35. Behtash N, Zarchi MK, Deldar M. Preoperative prognostic factors and effects of adjuvant therapy on outcomes of early stage cervical cancer in iran. Asian Pac J Cancer Prev. 2009;10:613-8.

36. Shahriarirad R, Khodamoradi Z, Khodamoradi Z, Erfani A, Erfani A, Hosseinpour $\mathrm{H}$, et al. Epidemiological and clinical features of 2019 novel coronavirus diseases (COVID-19) in the South of Iran. BMC Infect Dis. 2020;20:427.

37. Nikpouraghdam M, Jalali Farahani A, Alishiri GH, Heydari S, Ebrahimnia M, Samadinia H, et al. Epidemiological characteristics of coronavirus disease 2019 (COVID-19) patients in IRAN: A single center study. J Clin Virol. 2020;127:104378.

38. Javanian M, Bayani M, Shokri M, Sadeghi-Haddad-Zavareh M, Babazadeh A, Yeganeh B, et al. Clinical and laboratory findings 
from patients with COVID-19 pneumonia in Babol North of Iran: a retrospective cohort study. Rom J Intern Med. 2020;58:161-7.

39. Emami A, Javanmardi F, Akbari A, Moghadami M, Bakhtiari H, Falahati F, et al. Characteristics of deceased patients with CoVID19 after the first peak of the epidemic in Fars province, Iran. Infect Ecol Epidemiol. 2020;10:1781330.

40. Akbariqomi M, Hosseini MS, Rashidiani J, Sedighian H, Biganeh $\mathrm{H}$, Heidari R, et al. Clinical characteristics and outcome of hospitalized COVID-19 patients with diabetes: A single-center, retrospective study in Iran. Diabetes Res Clin Pract. 2020;169:108467.

41. Rastad H, Karim H, Ejtahed HS, Tajbakhsh R, Noorisepehr M, Babaei M, et al. Risk and predictors of in-hospital mortality from COVID-19 in patients with diabetes and cardiovascular disease. Diabetol Metab Syndr. 2020;12:57.

42. Papizadeh S, Moradi P, Mehr MH, Amerkani S, Nezhad RF, Saadati H, et al. Epidemiologic and clinical characteristics of 186 hospitalized patients with Covid-19 in Tehran, Iran: A retrospective, single-center case series. Preprints 2020, 2020070060.

43. Mirsoleymani S, Mojtaba S, Nekooghadam MA, Marzaleh M, Peyravi AS, Simintaj Sharififar R, et al. Assessment of risk factors for severe Coronavirus Disease 2019 among Iranian patients. Iran Red Crescent Med J. 2020;22(2):e72. https://doi.org/10.32592/ ircmj.2020.22.9.72.

44. Pazoki M, Keykhaei M, Kafan S, Montazeri M, Mirabdolhagh Hazaveh M, Sotoodehnia M, et al. Risk indicators associated with in-hospital mortality and severity in patients with diabetes mellitus and confirmed or clinically suspected COVID-19. J Diabetes Metab Disord. 2021;1-11. https://doi.org/10.1007/s40200-020-00701-2.

45. Bown MJ, Sutton AJ. Quality control in systematic reviews and meta-analyses. Eur J Vasc Endovasc Surg. 2010;40:669-77.

46. Sayed S. COVID-19 and diabetes; Possible role of polymorphism and rise of telemedicine. Prim Care Diabetes. 2020;15:4-9.

47. Leon-Abarca JA, Memon R, Rehan B, Iftikhar M, Chatterjee A. The impact of COVID-19 in diabetic kidney disease and chronic kidney disease: A population-based study. Acta Bio Medica Atenei Parmensis. 2020;91:e2020161-1.

48. Albulescu R, Dima S, Florea I, Lixandru D, Serban A, Aspritoiu V, et al. COVID-19 and diabetes mellitus: Unraveling the hypotheses that worsen the prognosis (Review). Exp Ther Med. 2020;20:1-1.

49. Das S, Anu K, Birangal SR, Nikam AN, Pandey A, Mutalik S, et al. Role of comorbidities like diabetes on severe acute respiratory syndrome coronavirus-2: A review. Life Sci. 2020;258:118202.

50. Li S, Wang J, Zhang B, Li X, Liu Y. Diabetes mellitus and causespecific mortality: A population-based study. Diabetes Metab J. 2019;43:319-41.

51. Al-Rubeaan K, Youssef AM, Ibrahim HM, Al-Sharqawi AH, AlQumaidi H, AlNaqeb D, et al. All-cause mortality and its risk factors among type 1 and type 2 diabetes mellitus in a country facing diabetes epidemic. Diabetes Res Clin Pract. 2016;118:130 9.

52. Dastgheib SA, Najafi F, Shajari A, Bahrami R, Asadian F, Sadeghizadeh-Yazdi J, et al. Association of plasminogen activator inhibitor-1 4G5G Polymorphism with risk of diabetic nephropathy and retinopathy: a systematic review and meta-analysis. J Diabetes Metab Disord. 2020;19(2):2005-16.
53. Huang I, Lim MA, Pranata R. Diabetes mellitus is associated with increased mortality and severity of disease in COVID-19 pneumonia - A systematic review, meta-analysis, and meta-regression: Diabetes and COVID-19. Diabetes Metab Syndr Clin Res Rev. 2020;14:395-403.

54. Barron E, Bakhai C, Kar P, Weaver A, Bradley D, Ismail H, et al. Associations of type 1 and type 2 diabetes with COVID-19-related mortality in England: a whole-population study. Lancet Diabetes Endocrinol. 2020;8:813-22.

55. Kolhe NV, Fluck RJ, Selby NM, Taal MW. Acute kidney injury associated with COVID-19: A retrospective cohort study. PLoS Med. 2020;17:e1003406.

56. Sooriakumaran P, Kaba R. The risks and benefits of cyclooxygenase- 2 inhibitors in prostate cancer: A review. Int J Surg. 2005;3:278-85.

57. Adapa S, Chenna A, Balla M, Merugu GP, Koduri NM, Daggubati SR, et al. COVID-19 pandemic causing acute kidney injury and impact on patients with chronic kidney disease and renal transplantation. J Clin Med Res. 2020;12:352-61.

58. Cai R, Zhang J, Zhu Y, Liu L, Liu Y, He Q. Mortality in chronic kidney disease patients with COVID-19: a systematic review and meta-analysis. Int Urol Nephrol. 2021;1-7. https://doi.org/10.1007/ s11255-020-02740-3.

59. Wang B, Li R, Lu Z, Huang Y. Does comorbidity increase the risk of patients with COVID-19: evidence from meta-analysis. Aging. 2020;12:6049-57.

60. Sabatino J, De Rosa S, Di Salvo G, Indolfi C. Impact of cardiovascular risk profile on COVID-19 outcome. A meta-analysis. Ricottini E, editor. PLoS One. 2020;15:e237131.

61. Hessami A, Shamshirian A, Heydari K, Pourali F, Alizadeh-Navaei $\mathrm{R}$, Moosazadeh $\mathrm{M}$, et al. Cardiovascular diseases burden in COVID-19: Systematic review and meta-analysis. Am J Emerg Med. 2020;S0735-6757:30908-6.

62. Khan MS, Shahid I, Anker SD, Solomon SD, Vardeny O, Michos ED, et al. Cardiovascular implications of COVID-19 versus influenza infection: a review. BMC Med. 2020;18(1):403. https://doi. org/10.1186/s12916-020-01816-2.

63. Fisher M. Cardiovascular disease and cardiovascular outcomes in COVID-19. Practical Diabetes. 2020;37:191.

64. Momtazmanesh S, Shobeiri P, Hanaei S, Mahmoud-Elsayed H, Dalvi B, Malakan Rad E. Cardiovascular disease in COVID-19: a systematic review and meta-analysis of 10,898 patients and proposal of a triage risk stratification tool. Egypt Heart J. 2020;72:41.

65. Hippisley-Cox J, Young D, Coupland C, Channon KM, Tan PS, Harrison DA, et al. Risk of severe COVID-19 disease with ACE inhibitors and angiotensin receptor blockers: Cohort study including 8.3 million people. Heart. 2020;106:1503-11.

66. Iaccarino G, Grassi G, Borghi C, Ferri C, Salvetti M, Volpe M. Age and multimorbidity predict death among COVID-19 patients: results of the SARS-RAS study of the Italian Society of Hypertension. Hypertension. 2020;76:366-72.

Publisher's note Springer Nature remains neutral with regard to jurisdictional claims in published maps and institutional affiliations. 